\title{
PAH QUANTIFICATION AND ESTIMATED CARCINOGENIC RISKS AT SELECTED FUEL STATIONS IN TAMALE METROPOLIS, GHANA
}

\author{
S. A. Ofori*, S. J. Cobbina And A. Z. Imoro \\ (S. A. O., S. J. C. \& A. Z. I.: Department of Ecotourism and Environmental Management, \\ Faculty of Natural Resources and Environment, University for Development Studies, Tama- \\ le, Ghana; S. A. O.: Department of Biology of Organisms, Faculty of Science, Université \\ Libre de Bruxelles, Brussels, Belgium; S. A. O.: Department of Biology, Faculty of Science \\ and Bioengineering Sciences, Vrije Universiteit Brussel, Brussels, Belgium; S. A. O.: De- \\ partment of Botany, Faculty of Science, University of Ruhuna, Matara, Sri Lanka.) \\ *Corresponding author's email: ofori496@gmail.com
}

\begin{abstract}
The research aim was to quantify PAHs levels and assess their associated carcinogenic health risks in fuel filling stations located in both high and low vehicular traffic areas in the Tamale Metropolis of Ghana. Dust particles were collected from ten fuel filling stations and extracted using an Accelerated Solvent Extractor (ASE). PAH analysis was conducted using a GC-MS system. Cancer risk assessment was done using the Incremental Life-time Cancer Risk (ILCR) model. The average PAH concentration recorded in the high and low vehicular traffic areas were $158,080 \pm 102,650 \mu \mathrm{g} / \mathrm{kg}$ and 370,220 $\pm 218,140 \mu \mathrm{g} / \mathrm{kg}$ respectively. Benzo(a)Anthracene was the most occurring PAH congener recorded in both traffic areas. Dermal contact as a route of PAH exposure recorded the highest potential cancer risk for both adults and children. Amongst the fuel filling stations, Gab Energy recorded the highest carcinogenic risks of 2.50 (adults) and 2.67 (children). In all, the average cancer risk values for adults (1.02) was slightly higher than that of the children (9.26E-01) with no significant difference. The mean $\Sigma$ ILCR values for both populations indicated a high to very high potential carcinogenic risk to the people living or working in and around the study areas.
\end{abstract}

Keywords: PAHs, fuel filling stations, dust particles, incremental lifetime cancer risk, Benzo(a)Anthracene.

\section{Introduction}

Polycyclic aromatic hydrocarbons (PAHs) are a group of organic compounds occurring naturally in resources such as crude oil, gasoline and coal which are introduced into the environment especially through incomplete combustion of organic substances (CDC, 2009). PAHs can be commonly identified in every part of the environment; from soil media, air mixtures, and water sources, and with their traces found in various food products, thereby characterising them as ubiquitous chemicals in the environment (Ofori et al., 2020).

PAHs are described as organic chemicals having a range of environmental properties which are determined by the amount of 
benzene rings and the molecular weight they possess (Stogiannidis \& Laane 2015). PAH congeners having four or more benzene rings are categorised as High Molecular Weight (HMW) PAHs, whereas those possessing two to three benzene rings are categorised as Low Molecular Weight (LMW). Some examples of LMW PAHs include Fluorene, Anthracene, Naphthalene, Phenanthrene, while other congeners such as Indeno[1,2,3-cd]pyrene, Chrysene, Pyrene, Benzo[a]pyrene, and Benz[a] anthracene and are described as HMW PAHs (Stogiannidis \& Laane, 2015; Ofori et al., 2020).

Law et al. (2002) noted that the LMW PAHs stay less longer in the environment due to their high volatility, and their low ability to dissolve in water. On the other hand, HMW PAHs are identified to be persistent in the environment as a result of their low volatile ability and their high resistance to undergo oxidation (Stogiannidis \& Laane, 2015). They are also described as being more water-insoluble when present as a mixture with alkyl substituent groups, making them strongly carcinogenic and mutagenic (Nkansah, 2012).

The ubiquitous and carcinogenic nature of PAHs in both indoor and outdoor environments are indicated to constitute a significant risk to public health as their exposure could lead to their uptake into the human body via inhalation, ingestion of food or water, soil, and/or via the skin. Public exposure to PAHs could lead to short- and long-term health effects, particularly associated with breathing and cardiovascular symptoms or ailments (Błaszczyk et al., 2016).

In Africa, PAH emissions from Nigeria and the Democratic Republic of Congo ranked $4^{\text {th }}$ and $8^{\text {th }}$ respectively considering the worldwide view in a report provided by Zhang and Tao (2009) in 2004. One of the reasons that put Nigeria as one of the top countries contributing to the global PAH pollution was the frequent incidents of oil pollution occurring in the Niger Delta (Ofori et al., 2020).

In Africa, a high number of studies have been done in assessing the occurrence and concentration levels of PAHs in various environmental samples as well as the risks they pose to public health. Most of the studies have focused on PAH pollution in agricultural soils, street soils, smoked fish and meat, food items, indoor and outdoor air, water bodies, among others (Ofori et al., 2020). However, only one study has been identified to focus on PAH pollution in fuel filling stations by assessing the levels of PAH pollution in the Calabar Metropolis of Nigeria (Nganje et al. 2007). In Ghana, no such study had yet been conducted.

In fuel filling stations, where there are countless records of both entries and exits of various vehicles for the purchase of different fuel products, the situation of PAH pollution appears to be common. Higher levels of PAH pollution in this area could be recorded due to observed instances of frequent fuel leakages from fuel dispensers or from faulty vehicular fuel tanks, as well as emissions of exhaust fumes from vehicles that visit or are located in the vicinity of the fuel filling stations. The risk of PAH exposure in the Tamale Metropolis is aggravated by the fact that, some heavy-duty vehicles use some of these stations as parking lots. This presents a high likelihood for fuel leakage and emissions from these vehicles which could thereby be classified as another contributor of PAH pollution into the vicinity. It has also been reported that automobiles, particularly heavy-duty vehicles in the Tamale Metropolis release high concentrations of PAHs into the atmosphere through their exhaust fumes (Obiri et al., 2011). These incidents of PAH pollution collectively create health hazards for workers, customers and people living closer to the fuel filing stations. The limited study in PAH pollution in fuel filling stations in the African continent has creat 
ed a knowledge gap in literature which needs to be tackled with. Moreover, in view of the need to promote public education on the potential health risks associated with PAH pollution, it was found necessary to conduct this research by assessing the concentration levels and potential carcinogenic health risks associated with the exposure to PAHs at fuel filling stations located in the Tamale Metropolis of Ghana.

\section{Study area}

\section{Experimental}

The study was conducted in Tamale Metropolis which is located in the Northern Region of Ghana. The Metropolis is situated at the central part of the region, sharing boundaries with the Sagnarigu District (West and North direction), Mion District (East direction), and East Gonja (South-West direction). It has a total land size of about $646.9 \mathrm{~km}^{2}$ and a geographical location between latitude $09^{\circ} 16$ and $09^{\circ} 34$ North and longitude $00^{\circ} 57$ West. The population of the Metropolis as at 2010 was 233,252 (49.7\% males and $50.3 \%$ females), corresponding to $9.4 \%$ of the regional population with majority being young people (almost $36.4 \%$ of the population is below 15 years) (Ghana Statistical Service, 2014).

\section{Selected Fuel Filling Stations in the Tamale Metropolis}

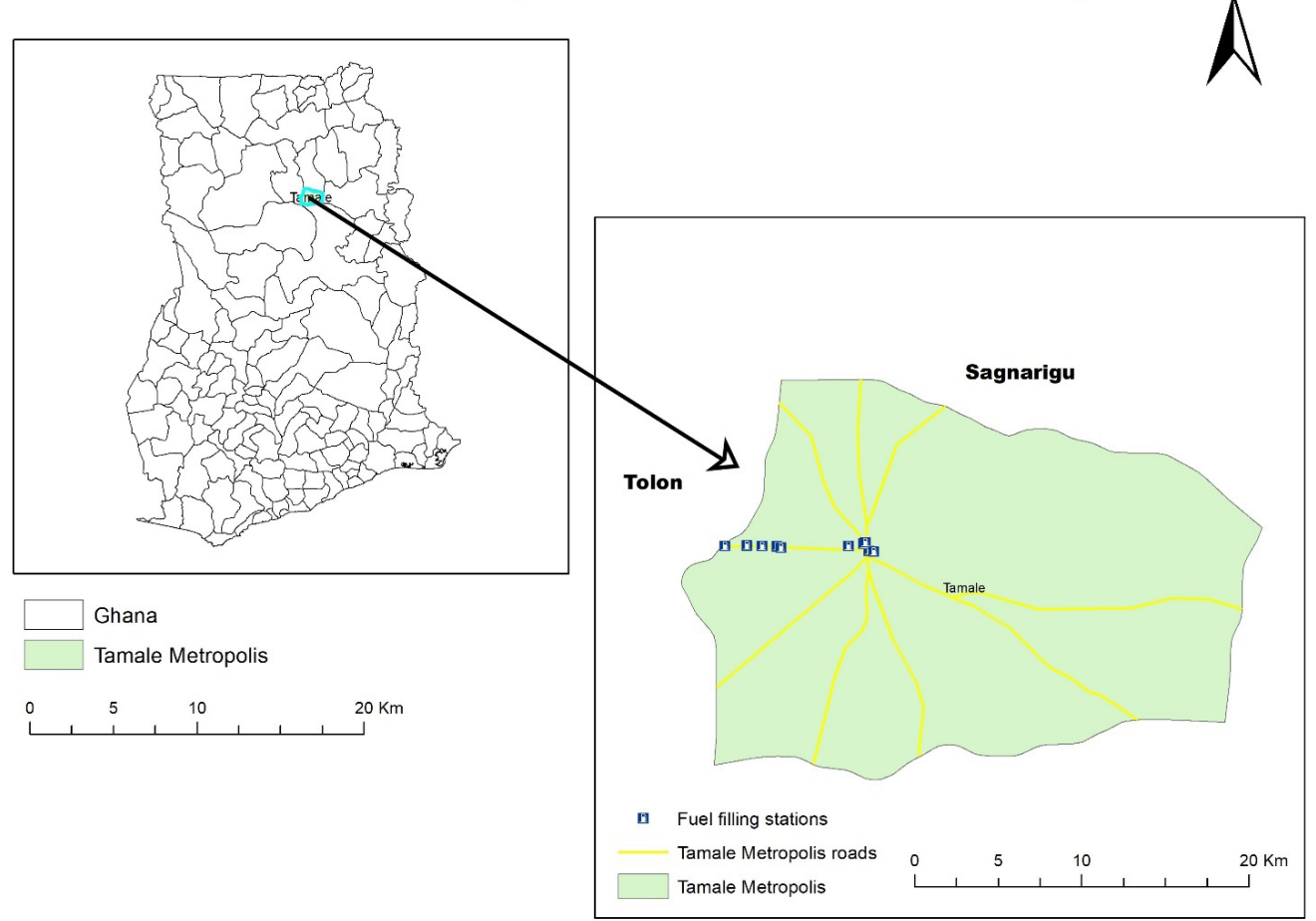

Fig. 1: Tamale Metropolis Showing Selected Fuel Filling Stations. 
Selection of fuel filling station and sampling technique

This study was conducted in fuel filling stations. For the purpose of this study, fuel filling stations were categorised under High-Vehicular Traffic Areas (H-VTA) and Low-Vehicular Traffic Areas (L-VTA) based on the following parameters:

- Fuel filling stations are close to or far from traffic light system(s)

- Fuel filling stations are close to or far from areas with continuous vehicular traffic

- Fuel filling stations are located in the centre or outskirts of Metropolis

Thus, an area where traffic light system(s) were present was categorised as a H-VTA, and the area without a traffic light system was categorised as a L-VTA. Also, an area where one could find recurrent vehicular traffic jams was categorised as a H-VTA, whereas an area without any occurrence of vehicular traffic jams was categorised as a L-VTA. Moreover, an area with more business activities involving high vehicular movements and located in the centre of the Metropolis was categorised as a H-VTA, while an area with relatively less busy nature and located away from the Metropolis centre was categorised as L-VTA.

In this view, ten fuel filling stations (five from each category) which were able to fully meet the criteria for selection were used in this study (Table 3).

\section{Sample collection}

The samples were collected in the dry season from $19^{\text {th }}$ to $21^{\text {st }}$ February 2018, between the hours of $6 \mathrm{pm}$ and $8 \mathrm{pm}$. This was the best time to find as much dust particles accumulated in the day. Frequent incidences of fuel leakages coupled with the accumulation of dust particles as blown by the dry winds towards the fuel dispensing area gave an indication of a major occurrence of PAH pollution in that area. Therefore, at each fuel filling station, two samples of $20 \mathrm{~g}$ each were collected mainly from the fuel dispensing area by sweeping dust particles with a pre-cleaned brush unto a precleaned dustpan. The fuel dispensing area is described as the space where drivers stop with their vehicles in order to be served, as well as the area around the fuel dispensing machine. Samples were then collected into $15 \mathrm{~mL}$ amber glass vials which had already been washed with de-ionised water and covered with aluminium foil. To prevent cross contamination of samples collected from each fuel filling station, the brush and dustpan had to be precleaned before sampling in each fuel filling station. The glass vials were later labelled and then enfolded with aluminium foil and preserved at an average temperature of $4{ }^{\circ} \mathrm{C}$ in an ice chest and transported to the laboratory for analyses.

\section{Sample Preparation and extraction}

Sample preparation and extraction was done according to protocol recommended by ElKady et al. (2018). Sample pairs collected from each fuel filling station were added as a composite sample and homogenised by sieving them through a $250 \mu \mathrm{m}$ mesh to remove stones and unwanted particles present. A sample mixture was prepared with a 3:1 ratio of 30 $\mathrm{g}$ of each sample composite to $10 \mathrm{~g}$ of diatomaceous earth (DE) to effect homogeneity and dryness. Extraction was carried out using the Dionex Accelerated Solvent Extractor (ASE) 350 with a solvent mixture comprising of 60 $\mathrm{mL}$ each of methanol and acetone $(\mathrm{v} / \mathrm{v} ; 1: 1)$ per sample extract. The method and sequence of extraction was programmed according to the following order:

- Temperature; $100^{\circ} \mathrm{C}$, Static time; $5 \mathrm{~m}$, Cycles; 3 , Rinse volume; $20 \%$, Purge; 30 s.

\section{Sample clean-up and analysis}

The clean-up process was done using a rotary evaporator. Sample extracts were concentrated 
to a volume of $1 \mathrm{~mL}$ at a temperature between $40-45{ }^{\circ} \mathrm{C}$ under a gentle stream of nitrogen gas. All samples were analysed under the same instrumental conditions defined by USEPA standards (USEPA, 1999).

The Agilent Technologies GC-MS system (GC 7890B and MS 7000C) was used to identify the presence and concentrations of PAH congeners in the sample extracts. A 2.0 $\mu \mathrm{L}$ of each sample extract was injected into the GC-MS system using the Agilent Split/Splitless inlet with a split time of 1 min after injection and at an inlet temperature set at $280^{\circ} \mathrm{C}$. The oven temperature programme was initially held at $80^{\circ} \mathrm{C}$ for $0.5 \mathrm{~min}$, then increased to $230^{\circ} \mathrm{C}$ at $80^{\circ} \mathrm{C} / \mathrm{min}$, and finally increased to $280^{\circ} \mathrm{C}$ at $5^{\circ} \mathrm{C} / \mathrm{min}$ (held at $5 \mathrm{~min}$ ) with a run time of $33.648 \mathrm{~min}$. Helium was used as the carrier gas with a column flow rate of 1 $\mathrm{mL} / \mathrm{min}$. The MS mode of operation was in the electron impact ionisation mode at $70 \mathrm{eV}$ with selected ion monitoring at a temperature of $230^{\circ} \mathrm{C}$. After all semi-volatile target compounds were eluted from the GC, the MS data acquisition was terminated, and data files were stored on the data system storage device.

The resulting limit of detection (LOD), which is calculated as three times the standard deviations of the blank sample, was recorded as $1.00 \mu \mathrm{g} / \mathrm{kg}$ for all the $16 \mathrm{PAHs}$ that were present in the samples.

\section{Health risk assessment}

Mutagenicity and carcinogenicity of PAHS

The MEQ and TEQ levels for the sum of the PAHs were calculated using defined values of MEF and TEF with the following equations;

$$
\begin{aligned}
& M E Q=\sum_{i=1}^{n}(\mathrm{PAH}) i \times M E F \\
& T E Q=\sum_{i=1}^{n}(\mathrm{PAH}) i \times T E F
\end{aligned}
$$

Where MEQ is Mutagenic Equivalent, TEQ is Carcinogenic Equivalent, MEF is Mutagenic
Equivalence Factor and TEF is Carcinogenic Equivalence Factor.

\section{Cancer risk assessment}

The incremental lifetime cancer risk (ILCR) model (USEPA, 1989) developed for quantitative estimation of exposure risks to PAHs was adopted in this study using the following assumptions:

i. Exposure to PAHs in the fuel filling stations is via ingestion of dust particles, dermal contact and direct inhalation of particulate matter,

ii. Overall cancer risk could be estimated by adding up the individual risks calculated for the respective exposure pathways,

iii. The carcinogenic risk is evaluated based on exposure in reference to the type of land use pattern (i.e. fuel filling stations) over the entire lifetime.

The assessment models recommended by the Risk Assessment Guidance of USEPA (1989) and adapted by Yang et al. (2015) and Bandowe and Nkansah (2016) were used to evaluate the ILCR in terms of ingestion, dermal contact and inhalation for both children and adults:

$$
\begin{aligned}
& \operatorname{ILCRs}_{\text {(inhalation) }}= \\
& \frac{C S \times\left(C S F_{\text {in hilation }} \times \sqrt[3]{\frac{B W}{70}}\right) \times I R_{\text {inhalation }} \times E F \times E D}{B W \times A T \times P E F} \\
& \frac{C S \times\left(C S F_{\text {dermal }} \times \sqrt[8]{\frac{B W}{70}}\right) \times S A \times A F \times A B S \times E F \times E D}{B W \times A T \times 10^{6}} \\
& \frac{C S \times\left(C S F_{\text {ingestion }} \times \sqrt[3]{\frac{D W}{70}}\right) \times I R_{\text {ingestion }} \times E F \times E D}{B W \times A T \times 10^{6}}
\end{aligned}
$$

Where CSF is carcinogenic slope factor $(\mathrm{mg} /$ $\mathrm{kg} /$ day); $\mathrm{CSF}_{\text {Ingestion }}, \mathrm{CSF}_{\text {Dermal }}$ and $\mathrm{CSF}_{\text {Inhalation }}$ of $\mathrm{B}(\mathrm{a}) \mathrm{P}$ were addressed as $7.3,25$, and 3.85 re- 
spectively, determined by the cancer-causing ability of B(a)P. CS $(\mu \mathrm{g} / \mathrm{kg})$ is the sum of the PAHs concentrations of the samples based on Toxic Equivalents (TEQ) of B(a)P using the Toxic Equivalency Factor (TEF) (Bandowe \& Nkansah, 2016).

Bandowe \& Nkansah (2016) provides a qualitative description of the ILCR as follows; a value which is $\leq 10^{-6}$ represents a very low cancer risk, a value ranging from $10^{-6}$ to $10^{-4}$ represents a low cancer risk, a value ranging from $10^{-3}$ to $10^{-1}$ represents a high cancer risk, and a value $\geq 10^{-1}$ represents a very high risk. The Table below provides the parameters used in the incremental lifetime cancer risk (ILCR) assessment.

\section{TABLE 1}

Parameters used in ILCR Assessment

\begin{tabular}{lllll}
\hline Exposure variable & Unit & Adult & Child & Reference \\
\hline $\begin{array}{l}\text { Exposure frequen- } \\
\text { cy (EF) }\end{array}$ & $\begin{array}{l}\text { day } \\
\text { year }{ }^{-1}\end{array}$ & 350 & 350 & USEPA (2001) \\
$\begin{array}{l}\text { Exposure duration } \\
\text { (ED) }\end{array}$ & year & 30 & & USEPA (2001) \\
$\begin{array}{l}\text { Body weight } \\
\text { (BW) }\end{array}$ & $\mathrm{kg}$ & 70.8 & 6 & Shirazu et al., 2017; Vuvur \\
& & 15 & and Harrison (2017), Band- \\
owe and Nkansah (2016)
\end{tabular}




\section{Results and discussion}

$16 \mathrm{PAH}$ congeners were identified using $\mathrm{GC} /$ MS as presented in Table 2. Amongst the 16 PAHs identified, Benzo(a)Anthracene recorded the highest concentrations in both H-VTAs (56.27\%) and L-VTAs (53.62\%) (Table 2). This agrees with the results of Essumang et al. (2016) and Franco et al. (2017) which indicate Benzo(a)Anthracene as the commonest PAHs in most environments. The prevalence of Benzo(a)Anthracene presents a carcinogenic risk to the health of the people living or working in the vicinity of the fuel filling stations since Benzo(a)Anthracene is listed by the International Agency for Research on Cancer (IARC) as a Class 2B carcinogenic compound (JRCIRMM, 2011). The National Cancer Institute Thesaurus (2019) confirms the common sources of Benzo(a)Anthracene production to be wood and soot smoke, gasoline and diesel exhaust, as well as coal tar and coal tar pitch. These common sources are nowhere exclusive from certain human activities including the combustion of gasoline and diesel in vehicles, the burning activities of sawmills, bush burning activities and the singeing activities of abattoirs, all occurring in neighbouring communities to some of the sampling sites.

In the study conducted by Obiri et al. (2011) on $\mathrm{PAH}$ pollution in road dusts sampled from the Tamale Metropolis, higher mean PAH concentration were recorded in H-VTA as compared to L-VTA. In the current study, it was identified that fuel filling stations in L-VTA rather recorded higher mean PAH concentration than those of the H-VTA (Table 2). Since this study deals with fuel filling stations, a number of factors may come into play to influence the total concentration of PAHs produced. For instance, Gab Energy which is located in the L-VTA recorded the highest concentration of PAHs amongst all the other fuel filling stations. It was observed that this station was visited more often by heavy-duty vehicles like trucks and buses, and directly served as a parking lot for them overnights. Also, many vehicular users chose to purchase their fuels there because it was newly opened, and the fuel products sold there were relatively cheaper to the public. Moreover, wood and grass combustion could also be a contributing factor to the higher $\mathrm{PAH}$ concentrations in the L-VTA since Gab Energy and Star Oil in particular were located near local communities where bush burning was common during the dry seasons.

The mean B(a)P concentration levels recorded in this study were $74,735.22 \pm 41,038.98 \mu \mathrm{g} / \mathrm{kg}$ for L-VTA fuel filling stations and 3,890.56 \pm $1,688.48 \mu \mathrm{g} / \mathrm{kg}$ for H-VTA fuel filling stations. A study conducted by Nganje et al. (2007) on PAH pollution in surface soil present in four fuel filling stations located in the Calabar Metropolis of Nigeria recorded a mean B(a)P concentration ranging from 4 to $680 \mu \mathrm{g} / \mathrm{kg}$. Moreover, studies have been conducted on $\mathrm{PAH}$ pollution in street dust by Obiri et al. (2011) in the Tamale Metropolis (Ghana), Essumang et al. (2006) in the Kumasi Metropolis (Ghana), and Singh (2014) in Delhi (India) with recorded average B(a)P concentration levels of $10,900 \mu \mathrm{g} / \mathrm{kg}, 27,900 \mu \mathrm{g} / \mathrm{kg}$ and $365.7 \mu \mathrm{g} / \mathrm{kg}$ respectively. A comparison of the $\mathrm{B}(\mathrm{a}) \mathrm{P}$ concentration levels recorded in this study to those of the aforementioned studies indicated that the $\mathrm{B}(\mathrm{a}) \mathrm{P}$ pollution levels at fuel filling stations in the Tamale Metropolis is higher (Table 2). $\mathrm{B}(\mathrm{a}) \mathrm{P}$ is a common human carcinogen (WHO, 2010). Consequently, its high levels in fuel filling stations of the Tamale Metropolis should be of great concern. 
TABLE 2

Mean concentrations of individual PAHs in low and high-vehicular traffic area fuel filling stations

\begin{tabular}{|c|c|c|c|c|c|c|}
\hline \multirow[b]{2}{*}{ PAHs } & \multicolumn{4}{|c|}{ Low-Vehicular Traffic Area } & \multicolumn{2}{|c|}{ High-0Vehicular Traffic Area } \\
\hline & $\begin{array}{l}\text { Total Conc. } \\
(\mu \mathrm{g} / \mathrm{kg})\end{array}$ & $\begin{array}{l}\text { Mean } \\
\text { Conc. }(\mu \mathrm{g} / \\
\text { kg) }\end{array}$ & $\begin{array}{l}\text { Standard } \\
\text { Deviation } \\
(\mathrm{ug} / \mathbf{k g}) \\
\end{array}$ & $\begin{array}{l}\text { Total Conc. } \\
(\mu \mathrm{g} / \mathrm{kg})\end{array}$ & $\begin{array}{l}\text { Mean Conc. } \\
(\mu \mathrm{g} / \mathrm{kg})\end{array}$ & $\begin{array}{l}\text { Standard } \\
\text { Deviation } \\
(\mu \mathrm{g} / \mathbf{k g}) \\
\end{array}$ \\
\hline Naphthalene & 787.10 & 157.42 & 81.88 & 38.70 & 7.74 & 3.31 \\
\hline Acenaphthene & $43,787.20$ & $8,757.44$ & $4,855.22$ & $5,623.30$ & $1,124.66$ & 474.52 \\
\hline Acenaphthylene & 421.70 & 84.34 & 49.85 & 144.30 & 28.86 & 16.07 \\
\hline Fluorene & 305.10 & 61.02 & 33.98 & 62.40 & 12.48 & 4.67 \\
\hline Anthracene & $8,892.90$ & $1,778.58$ & 937.99 & $1,658.40$ & 331.68 & 144.43 \\
\hline Phenanthrene & $8,955.10$ & $1,791.02$ & 954.77 & $1,704.10$ & 340.82 & 149.76 \\
\hline Fluoranthene & $447,821.60$ & $89,564.32$ & $51,392.37$ & $82,482.20$ & $16,496.44$ & $8,952.67$ \\
\hline Pyrene & $1,782,923.20$ & $356,584.64$ & $220,423.35$ & $945,255.70$ & $189,051.14$ & $93,200.59$ \\
\hline Benzo(a)Anthracene & $3,176,397.80$ & $635,279.56$ & $278,810.95$ & $1,423,277.80$ & $284,655.56$ & $154,237.67$ \\
\hline Chrysene & $53,532.80$ & $10,706.56$ & $6,364.05$ & $47,903.90$ & $9,580.78$ & $5,303.57$ \\
\hline Benzo(a)Pyrene & $373,676.10$ & $74,735.22$ & $41,038.98$ & $19,452.80$ & $3,890.56$ & $1,688.48$ \\
\hline $\begin{array}{l}\text { Benzo(k)Fluoran- } \\
\text { thene }\end{array}$ & $1,731.50$ & 346.30 & 196.29 & 143.20 & 28.64 & 15.95 \\
\hline $\begin{array}{l}\text { Benzo(b)Fluoran- } \\
\text { thene }\end{array}$ & $15,318.20$ & $3,063.64$ & $1,751.32$ & 623.20 & 124.64 & 76.86 \\
\hline $\begin{array}{l}\text { Dibenzo[a,h]anthra- } \\
\text { cene }\end{array}$ & 989.30 & 197.86 & 90.48 & 233.30 & 46.66 & 29.19 \\
\hline $\begin{array}{l}\text { Indeno[ }[1,2,3, \mathrm{~cd}] \\
\text { pyrene }\end{array}$ & 957.10 & 191.42 & 91.92 & 249.60 & 49.92 & 30.75 \\
\hline Benzo[g,h,i]perylene & $7,035.00$ & 1,407 & 978.48 & 451.50 & 90.30 & 39.89 \\
\hline $\begin{array}{l}\text { Mean concentration } \\
(\mu \mathrm{g} / \mathrm{kg})\end{array}$ & $370,220.73$ & & & $158,081.53$ & & \\
\hline
\end{tabular}

The estimated average TEQs and MEQs for the various fuel filling stations were 86,074.267 $\mu \mathrm{g} / \mathrm{kg}$ and $77,836.93 \mu \mathrm{g} / \mathrm{kg}$ respectively (Table 3). In comparison to the average TEQs recorded in urban soils from Xi'an $(1,150 \mu \mathrm{g} /$ $\mathrm{kg})$, Guangzhou $(2,763 \mu \mathrm{g} / \mathrm{kg})$, and Tianjin $(4,554 \mu \mathrm{g} / \mathrm{kg})$ (Bandowe and Nkansah, 2016) which are known to be megacities in China, it provided an indication that PAH concentration levels in dust particles at fuel filling stations in Tamale Metropolis presented significantly higher potential carcinogenic effects. It is however important to note that since samples in this study were directly collected from fuel filling stations, there is a greater probability of recording high average values of TEQs and MEQs due to a larger contribution of localised source of pollution. 
Amongst the selected fuel filling stations, Gab Energy $(483,651.14 \mu \mathrm{g} / \mathrm{kg}$ and $452,219.52$ $\mu \mathrm{g} / \mathrm{kg})$ and Star Oil $(213,162.58 \mu \mathrm{g} / \mathrm{kg}$ and $188,536.77 \mu \mathrm{g} / \mathrm{kg}$ ) of the L-VTAs recorded the highest estimates of TEQs and MEQs respectively. This could be attributed to the fact that the two fuel filling stations served as parking lots for heavy-duty vehicles, and were also located close to local communities which oftentimes practiced bush burning during the dry seasons, leading to the high accumulation of PAHs in their vicinity. Among the H-VTA fuel filling stations, Goil [Melcom Branch] $(124,849.21 \mu \mathrm{g} / \mathrm{kg}$ and $104,008.07 \mu \mathrm{g} / \mathrm{kg})$ recorded the highest TEQ and MEQ values respectively. The high TEQ and MEQ values presented by Goil [Melcom Branch] could be as a reason of its location in the centre of the Tamale Business District, serving the greater portion of the public.

TABLE 3

Carcinogenicity and mutagenicity of identified PAHs

\begin{tabular}{|c|c|c|c|c|}
\hline $\begin{array}{l}\text { Area } \\
\text { Category }\end{array}$ & $\begin{array}{l}\text { Name of Fuel } \\
\text { Filling Station }\end{array}$ & $\begin{array}{l}\text { Average PAHs } \\
(\mu \mathrm{g} / \mathrm{kg})\end{array}$ & TEQ $(\mu \mathrm{g} / \mathrm{kg})$ & MEQ $(\mu \mathrm{g} / \mathrm{kg})$ \\
\hline \multirow{5}{*}{$\begin{array}{l}\text { High-Vehic- } \\
\text { ular Traffic } \\
\text { Area }\end{array}$} & Goil (Melcom Branch) & 192,454 & $124,849.21$ & $104,008.07$ \\
\hline & Total (CM Branch) & 587,067 & $37,158.94$ & $32,016.17$ \\
\hline & Goil (HR. Branch) & 5,635 & 507.50 & 420.04 \\
\hline & Total (HR. Branch) & 11,658 & $1,134.51$ & 933.13 \\
\hline & Shell (Aboabo Branch) & 396 & 0.78 & 0.91 \\
\hline \multirow{5}{*}{$\begin{array}{l}\text { Low-Vehic- } \\
\text { ular Traffic } \\
\text { Area }\end{array}$} & Gab Energy & $4,147,852$ & $483,651.14$ & $452,219.53$ \\
\hline & Star Oil & $1,772,030$ & $213,162.58$ & $188,536.77$ \\
\hline & Compass Oleum & 1,243 & 111.53 & 94.20 \\
\hline & Naagamni & 1,808 & 164.78 & 138.38 \\
\hline & Blanko Oil & 597 & 1.71 & 2.11 \\
\hline
\end{tabular}

Depending on the TEQs of the fuel filling stations as well as some relevant parameters mentioned in Table 1, a potential risk assessment framework was designed to estimate the risks posed to the people (adults and children) living and working in the vicinity of the fuel filling stations via exposure routes of inhalation, ingestion and dermal contact (Table 4). For adults, the estimated cancer risk via inhalation route of exposure ranged between $2.57 \mathrm{E}-10$ and $1.60 \mathrm{E}-04$, that of dermal contact ranged between 5.89E-06 and 3.65, and that of ingestion between 3.32E-06 and 2.06. For children, the estimated cancer risk via inhala- tion route of exposure ranged between 7.24E11 and 4.49E-05, that of dermal contact ranged between $4.65 \mathrm{E}-06$ and 2.89 , and that of ingestion between 3.73E-06 and 2.32. Of both populations, PAH exposure via inhalation route recorded the lowest value of cancer risk, while dermal route of exposure recorded the highest value of cancer risk. These findings agree with Yang et al. (2015) in China, Bandowe and Nkansah (2016) in Ghana, Tarafdar and Sinha (2018) in India, and Ghosh and Maiti (2019) in India, who stated that PAH exposure in urban soils via inhalation route posed the least potential cancer risk whereas exposure via der- 
mal contact recorded the highest risk for both adults and children. This is explained by the lower concentrations of the LMW PAHs such as Naphthalene, Phenanthrene, Anthracene and Fluorene recorded in this study. Although these PAH congeners are normally present in the atmosphere because of their high volatility, they are however present in lower levels (Law et al., 2002). In contrast, the HMW PAHs such as Pyrene, Benz[a]anthracene, and Benzo[a] pyrene which contributed greatly to the total PAH concentrations recorded in this study are less volatile with low mobility in organic matter (e.g. B[a]P $\log \mathrm{Koc}=6.6-6.8)(\mathrm{WHO}$, 2010; Stogiannidis and Laane, 2015).

A cancer risk value ranging from $10^{-3}$ to $10^{-1}$ represents a high cancer risk, while a value $\geq 10^{-1}$ represents a very high risk (Bandowe and Nkansah, 2016). The recorded cancer risk values in this study for both populations via ingestion and dermal pathways of exposure do explain that the associated population are potentially exposed to a high to very high cancer risk. The exposure of both groups to the identified PAHs can be linked with an increased risk of cancer development in different tissues of the body, including the lung, bladder, stomach, and skin (including the scrotum), depending on the mode of exposure and the type of PAH they are exposed to (CCME, 2010).

The higher carcinogenic risk values recorded by the adults via both inhalation and ingestion exposure pathways could be associated with their longer exposure duration especially during working hours. However, children are at a higher risk of acquiring cancer than the adult population due to their smaller body weight and their less developed immune system necessary to detoxify toxic chemicals. Once the PAHs are able to get into the body system of the children, they become more active in their systems and thus can interfere with organ development and proper operation of the central nervous system (Iwegbue et al., 2016). Moreover, the WHO (2010) stated that the incidental ingestion of soil by adult males is estimated to be of the order of a few milligrams per day, but that of the children were of the order of $100 \mathrm{mg} / \mathrm{day}$, re-emphasising the high risks the children population may be exposed to.

Amongst the fuel filling stations, Gab Energy recorded the highest carcinogenic risks of 5.71 (adults) and 5.21 (children), and then followed by Star Oil with 2.52 (adults) and 2.29 (children). The least carcinogenic risk was recorded at the Shell station with values of 9.21E-06 (adult) and 5.33E-05 (children). Ultimately, the average ILCR for adults (1.02) amongst all the fuel filling stations in both vehicular areas was slightly greater than that of the children (9.26E-01). An unpaired t-test conducted presented a p-value of 0.9226 at 95\% confidence level, indicating that there was no significant difference existing between the mean carcinogenic risk values recorded between adult and children populations. This gives a pressing issue of concern for both age groups, especially the children group who are more prone to effects from exposure to toxic chemicals. 


\section{Conclusions}

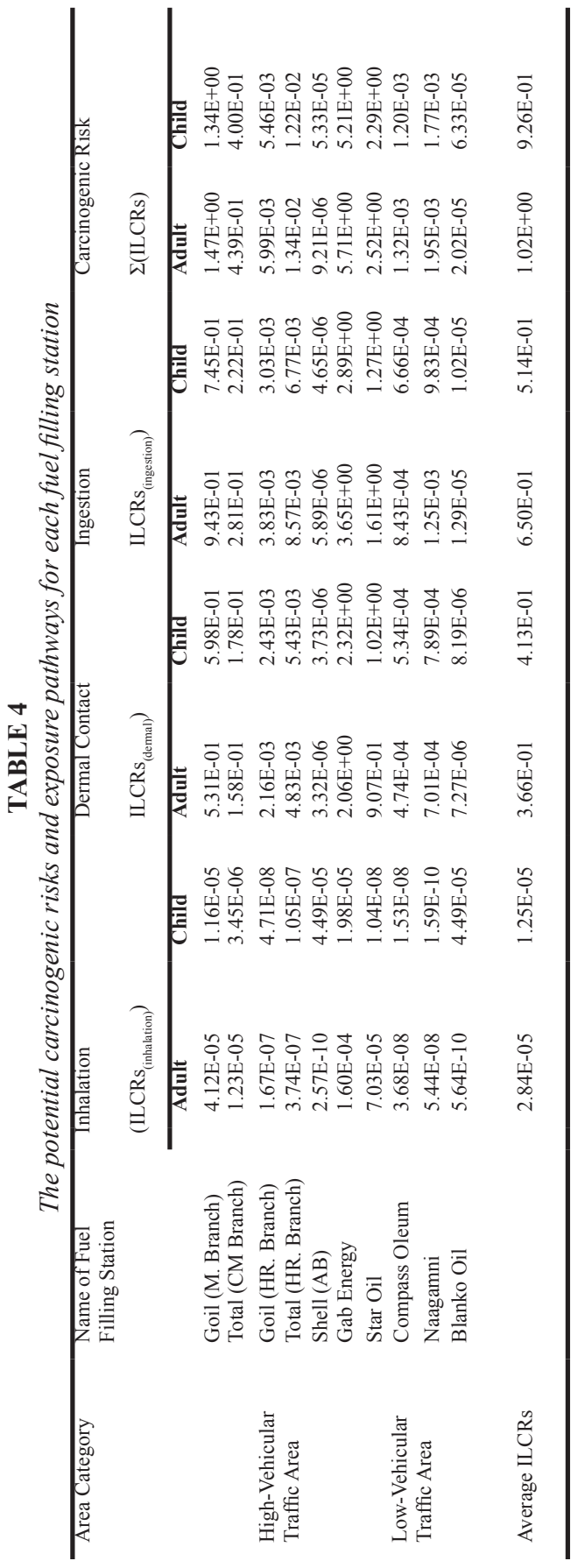

The identified PAHs in the dust particles present in the selected fuel filling stations were of high concentrations, especially Benzo(a)Anthracene and Pyrene which are of public health concern. Benzo(a)Pyrene which is identified as a common carcinogen recorded higher concentration levels when compared with similar studies conducted in major cities like Kumasi of Ghana, and Delhi of India. The exposure of associated population to the high PAH concentration levels recorded in this study is more through dermal pathway than that of ingestion or inhalation. The results indicate that there is a high potential risk of cancer to both adults and the children who work, patronise, or live around the fuel filling stations. It is therefore recommended that government agencies like the Environmental Protection Agency (EPA) and the National Petroleum Authority (NPA) take up effective measures to help control the high level of PAH pollution occurring in the fuel filling stations.

\section{Acknowledgments}

Our appreciation goes to Managers of the fuel filling stations in the Tamale Metropolis who gave us the needed support during our sample collection. We are also grateful to Mr. Desmond Nkansah of the Chemical Engineering Department of KNUST for helping in the extraction of samples, and to the Ghana Standards Authority for chemical analysis.

\section{References}

Agency For Toxic Substances And Disease Registry (AtSDR) (1995) Toxicological Profile for Polycyclic Aromatic Hydrocarbons. Atlanta, USA: US Department of Health \& Human Services, Public Health Service, Agency for Toxic Substances and Disease Registry 
Bandowe, B. A. M. \& Nkansah, M. A. (2016) Occurrence, Distribution and Health Risk from Polycyclic Aromatic Compounds (PAHs, Oxygenated-PAHs and Azaarenes) in Street Dust from a Major West African Metropolis. Science of the Total Environment 553, 439 - 449. https://doi.org/10.1016/j.scitotenv.2016.02.142

BŁaszczyk, E., Rogula-KozŁowska, W., KlejnowsKi, K., Fulara, I. \& Mielżyńska-Švach, D. (2016) Polycyclic Aromatic Hydrocarbons Bound to Outdoor and Indoor Airborne Particles (PM2.5) and Their Mutagenicity and Carcinogenicity in Silesian kindergartens, Poland. Air Quality, Atmosphere and Health 10, 389 - 400. https://doi:10.1007/s11869016-0457-5

Canadian Council Of Ministers Of The Environment (CCME) (2010) Canadian Soil Quality Guidelines for Carcinogenic and Other Polycyclic Aromatic Hydrocarbons (Environmental and Human Health Effects). Scientific Criteria Document (revised). $216 \mathrm{pp}$.

CENTRES FOR DISEASE CONTROL AND PREVENTION (2009) Polycyclic Aromatic Hydrocarbons Factsheet. Https://www.cdc. gov/biomonitoring/PAHs_FactSheet.html

Essumang, D. K., Dodoo, D. K., Obiri, S. \& Oduro, A. K. (2006) Analysis of Polycyclic Aromatic Hydrocarbons in Street Soil Dust in $\mathrm{Ku}-$ masi Metropolis of Ghana. Environmental Monitoring and Assessment 121, 401 - 408. https://doi: 10.1007/s10661-005-9137-x

Essumang, D. K., Dodoo, D. K., Ofori, J. \& Adjei, J. K. (2016) Polycyclic Aromatic Hydrocarbons in Settled Dust Particles in Selected Ghanaian Environments: Levels, Source Characterisation, and Assessment of Inhalational Health Risks. Indoor and Built Environment 25 (1), 242 - 253. https://doi: $10.1177 / 1420326$ X14544530

Franco, C. F. J., Fabri De Resende, M., Furtado, L., Brasil, T. F., Eberlin, M. N. \& Netto, A. D. P. (2017) Polycyclic Aromatic Hydrocarbons (PAHs) in Street Dust of Rio De Janei- ro and Niterói, Brazil: Particle Size Distribution, Sources and Cancer Risk Assessment. Science of the Total Environment $\mathbf{5 9 9}$ - 600, 305 - 313. https://doi.org/10.1016/j.scitotenv.2017.04.060

GERMAN FEDERAL ENVIRONMENT AGENCY (2012) Polycyclic Aromatic Hydrocarbons: Harmful to the Environment! Toxic! Inevitable? Https://www.umweltbundesamt.de

GHANA STATISTICAL SERVICE (GSS). (2014) District Analytical Report Tamale Metropolis: Population and housing census, 2010. Https://www.statsghana.gov.gh

Ghosh, S. P. \& Maiti, S. K. (2019) Evaluation of PAHs concentration and cancer risk assessment on human health in a roadside soil: A case study. Human and Ecological Risk Assessment: An International Journal, DOI:10.10 80/10807039.2018.1551052

Imegbue, C. M. A., Obi, G., Aganbi, E., Ogala, J. E., Omo-Irabor, O. O. \& Martincigh, B. S. (2016) Concentrations and Health Risk Assessment of Polycyclic Aromatic Hydrocarbons in Soils of an Urban Environment in the Niger Delta, Nigeria. Toxicol. Environ. Health. Sci. 8 (3), 221 - 233. https:// doi:10.1007/s13530-016-0279-8

LERDA, D. (2011) Joint Research Centre-Institute for Reference Materials and Measurements. Polycyclic Aromatic Hydrocarbons (PAHs) Factsheet, $4^{\text {th }}$ Edition. Available from https://ec.europa.eu/jrc/sites/jrcsh/files/ Factsheet\%20PAH_0.pdf Accessed on $15^{\text {th }}$ March, 2018

NATIONAL CANCER INSTITUTE (2019) Benz[a] anthracene. Available from https://ncit.nci. nih.gov/ncitbrowser/ConceptReport.jsp?dictionary=NCI_Thesaurus\&ns=NCI_Thesaurus\&code $=\bar{C} 44334$. Accessed on $4^{\text {th }}$ May, 2019.

NEW YORK STATE DEPARTMENT OF HEALTH (2012) Health consultation: Hopewell precision area groundwater contamination site town of East Fishkill, Dutchess County, New 
York. APPENDIX C, DOH Procedure for Evaluating Potential Health Risks for Contaminants of Concern.।

Nkansah, M. A. (2012) Environmental remediation: Removal of polycyclic aromatic hydrocarbons. PhD Thesis. University of Bergen. $2 p$

Obiri, S., Cobbina, S. J., Armah, F. A. \& NaAngmenyeLE, Z. (2011) Quantification and Characterization of Vehicle-Based Polycyclic Aromatic Hydrocarbons (PAHs) In Street Dust from The Tamale Metropolis, Ghana. Environmental Science Pollution Research 18, 1166 - 1173. https://doi:10.1007/s11356011-0465-9

Ofori, S. A., Cobbina, S. J. \& Doke, D. A. (2020) The Occurrence and Levels of Polycyclic Aromatic Hydrocarbons (PAHs) in African Environments - A Systematic Review. Environmental Science and Pollution Research 27. https://doi:10.1007/s11356-020-09428-2

Shirazu, I., Mensah, Y. B., Schandorf, C. \& MenSAH, S. Y. (2017) Determination of Standard Reference Body Indices for Clinical Application in Ghana. International Journal of Scientific \& Technology Research 6 (2).

Singh, D. (2014) Estimates of Polycyclic Aromatic Hydrocarbons and Other Indoor Air Pollutants Emitted from Biomass Fuels Used in Residential Sector of Northern India. PhD Thesis. University School of Basic and Applied Sciences. India. 252p

Stogiannidis, E. \& LaAne, R. (2015) Source characterization of polycyclic aromatic hydrocarbons by using their molecular indices: An overview of possibilities. Reviews of Environmental Contamination and Toxicology 234. https://doi.org/10.1007/978-3-319-106380_2

Tang, L., Tang, X-Y., Zhu, Y-G., Zheng, M-H. \& Miao, Q-L. (2005) Contamination of Polycyclic Aromatic Hydrocarbons (PAHs) in
Urban Soils in Beijing, China. Environment International 31, $822-828$. https:// doi:10.1016/j.envint.2005.05.031

TARAFDAR, A. \& SINHA, A. (2018) Health Risk Assessment and Source Study of PAHs from Roadside Soil Dust of a Heavy Mining Area in India. Archives of Environmental and $O c$ cupational Health. https://doi.org/10.1080 /19338244.2018.1444575

U.S. ENVIRONMENTAL PROTECTION AGENCY. (1989) Risk assessment guidance for superfund, vol. I: human health evaluation manual (Part A). I:291. DOI: EPA/540/1-89/002. USEPA, Washington, DC.

U.S. ENVIRONMENTAL PROTECTION AGENCY. (1999) Compendium of Methods for the Determination of Toxic Organic Compounds in Ambient Air (Compendium Method TO13A), $2^{\text {nd }}$ Edition: Determination of Polycyclic Aromatic Hydrocarbons (PAHs) in Ambient Air Using Gas Chromatography/ Mass Spectrometry (GC/MS). Cincinnati, $\mathrm{OH}$ 45268, USA: Winberry T. J. W. J. \& Jungclaus G.

U.S. ENVIRONMENTAL PROTECTION AGENCY. (2001) Supplemental guidance for developing soil screening levels for superfund sites 93554-24. Washington, D.C: Office of Emergency and Remedial Response.

VUVOR, F. \& HARRISON, O. (2017) Correlation between Body Weight and Total Body Fat Composition in Adults in A Community in Ghana. Mathews J Nutr Diet. 2 (1), 015

WORLD HEALTH ORGANIZATION (2010) WHO Guidelines for Indoor Air Quality: Selected Pollutants. WHO Regional Office for Europe Scherfigsvej 8 DK-2100 Copenhagen $\varnothing$, Denmark.

Yang, Q., Chen, H. \& Li, B. (2015) Polycyclic Aromatic Hydrocarbons (PAHs) in Indoor Dusts of Guizhou, Southwest of China: Status, Sources and Potential Human Health Risk. PLoS ONE 10 (2), e0118141. https:// doi:10.1371/journal.pone.0118141 